\section{Protective shield wins award}

Mats Norman, dentist and Head of Operations at Tandläkarna Norman in Uddevalla, Sweden, has been awarded the Gold Heart, a prize instituted by Praktikertjänst, in the category best innovation. Together with Orsing, Mats Norman developed his idea of CareShield: from PET-bottle to finished product.

CareShield is an easy-to-use transparent screen with an integrated HVE suction function that removes droplets and aerosols that harbour potentially dangerous pathogens.

During dental procedures, dentists, dental hygienists, dental nurses and patients are exposed to aerosols and organic fluids such as blood and saliva. These fluids spread and contaminate personal protective equipment as well as surfaces around the clinic. CareShield helps reduce cross contamination by removing aerosols and droplets through your HVE system during treatment. Easy to connect and use, CareShield ensures prevention contamination procedures for you and your patients.

For more information, visit www.orsing.se.

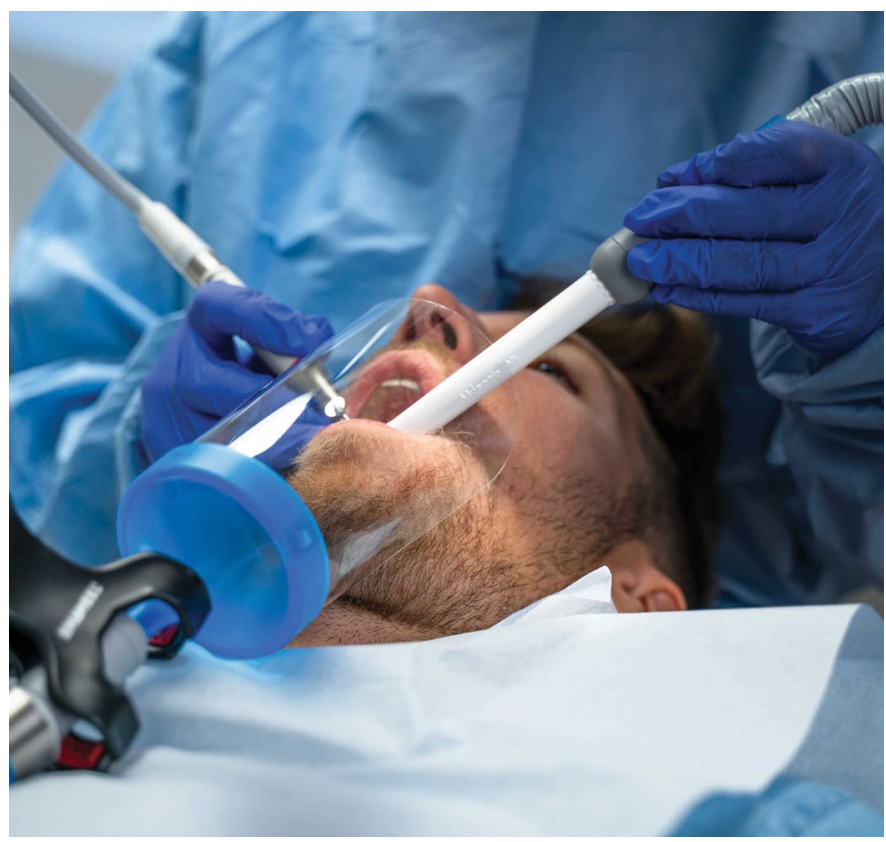

\section{A simple solution to your air supply}

Looking after your air supply shouldn't be complicated.

That's why DENTALAIR UTILITIES aims to revolutionise your air supply with Air to the Chair.

Air to the Chair is easy, all you need to do is log onto www.dentalair. com and select the 'New Air Supply' option from the top of the screen.

Following this, indicate how many chairs you need an air supply for and you will instantly be given a fixed subscription price. This includes a brand new air supply, written documentation to assist with inspections, regular maintenance and complete breakdown cover.

There are no credit checks necessary and DENTALAIR

UTILITIES always works around your schedule to provide an exceptional level of customer service!

To find out more, visit the DENTALAIR UTILITIES website.

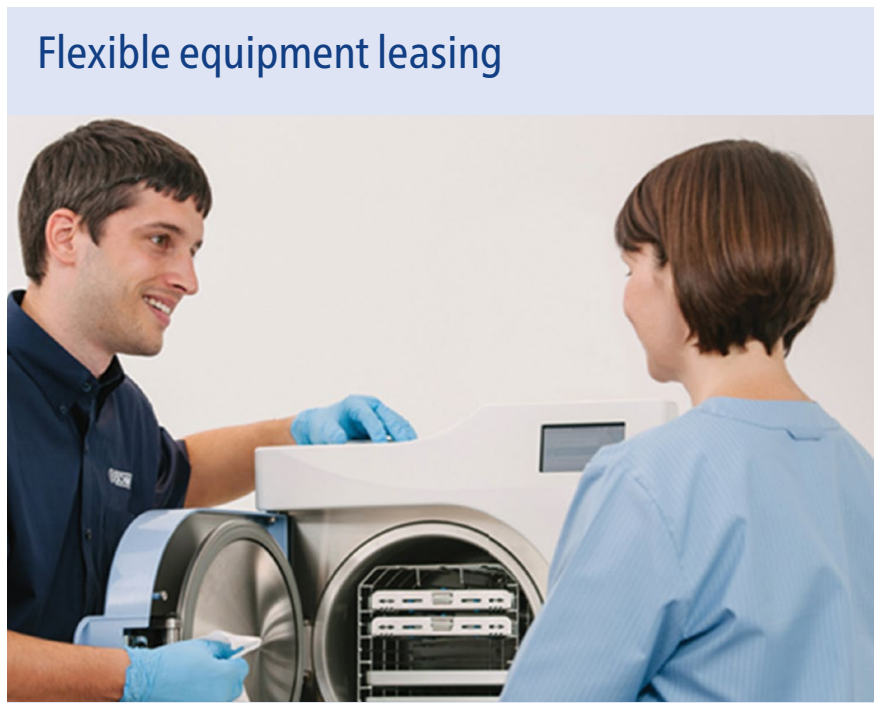

There are various reasons why leasing decontamination equipment may be a more suitable option for you.

With Eschmann's fully comprehensive lease plans, you can benefit from using cutting-edge systems on a more flexible basis. With 36-, 60-, and 84-month terms available, you can take out an option that suits you and aligns with your needs.

Plus, all of Eschmann's lease plans include their exceptional Care \& Cover contract. This completely protects your system and has the following benefits:

- Annual Validation \& Pressure Vessel Certification

- Annual Service \& Software Upgrade

- Unlimited Breakdown Cover

- Unlimited Eschmann Parts \& Labour

- Nationwide On-Site Support

- Enhanced CPD User Training

- Technical Telephone Support.

Find out more or speak to Eschmann today.

For more information on the highly effective and affordable range of infection control products from Eschmann, visit www. eschmann.co.uk or call 01903875787. 